\title{
PROPUESTA DE DISEÑO: EJE DE INTERCONEXIÓN Y REVITALIZACIÓN ENTRE PARQUES Parque Santander y el Parque Centenario en el Centro de Bucaramanga, Colombia
}

\author{
Autor: Natalia Andrea Cadena Casadiego \\ Universidad Santo Tomas, Seccional Bucaramanga \\ Director de la investigación: PhD. Diana Carolina Sevilla Torres \\ EMail: nataliacadena@hotmail.com
}

\begin{abstract}
RESUMEN
La intervención urbana propuesta entre el parque Santander y el parque Centenario ubicado en el Eje de la carrera 19 entre calles 31 y 36 del Centro de Bucaramanga, busca la creación de una red que interconecte y revitalice el espacio público, además de permitir el reconocimiento de un patrimonio edilicio existente dentro de los límites establecidos en el proyecto, bajo el referente teórico de Jan Gehl.

El proyecto enlaza una visión retrospectiva del lugar con una propuesta actual, que pretende responder a las transformaciones que ha experimentado dicho sector históricamente y que son reconocidas por estudiosos de la ciudad, como lo son su expansión no planificada y las actividades que lo convierten en un foco administrativo y comercial, que al mismo tiempo deterioran el espacio público.
\end{abstract}

Palabras Clave: Sector Centro, Intervención Urbana, Interconexión y Revitalización.

\begin{abstract}
The proposed urban intervention between Parque Santander and Parque Centenario located on the axis of the 19th street between streets 31 and 36 of the Bucaramanga downtown, seeks the creation of a network that interconnects and revitalizes the public space, as well as allowing the recognition of an existing building heritage within the limits established in the project, under the theoretical reference of Jan Gehl.

The project links a retrospective view of the place with a current proposal, which aims to respond to the transformations that the sector has experienced historically and which are recognized by scholars of the city, such as its unplanned expansion and the activities that make it an administrative and commercial focus, which at the same time deteriorate the public space.
\end{abstract}

Key Words: Downtown, Urban Intervention, Interconnection and Revitalization. 


\section{INTRODUCCIÓN}

La intervención urbana propuesta en el centro de Bucaramanga busca la interconexión y revitalización del eje que comunica al Parque Santander (1914) con el Parque Centenario (1910), localizado en la Carrera 19 entre Calles 31 y 36 . El sector ha experimentado transformaciones, por su proceso de expansión y sus dinámicas urbanas lo convirtieron en un foco administrativo y comercial que posteriormente generó el deterioro y la desarticulación del espacio público.

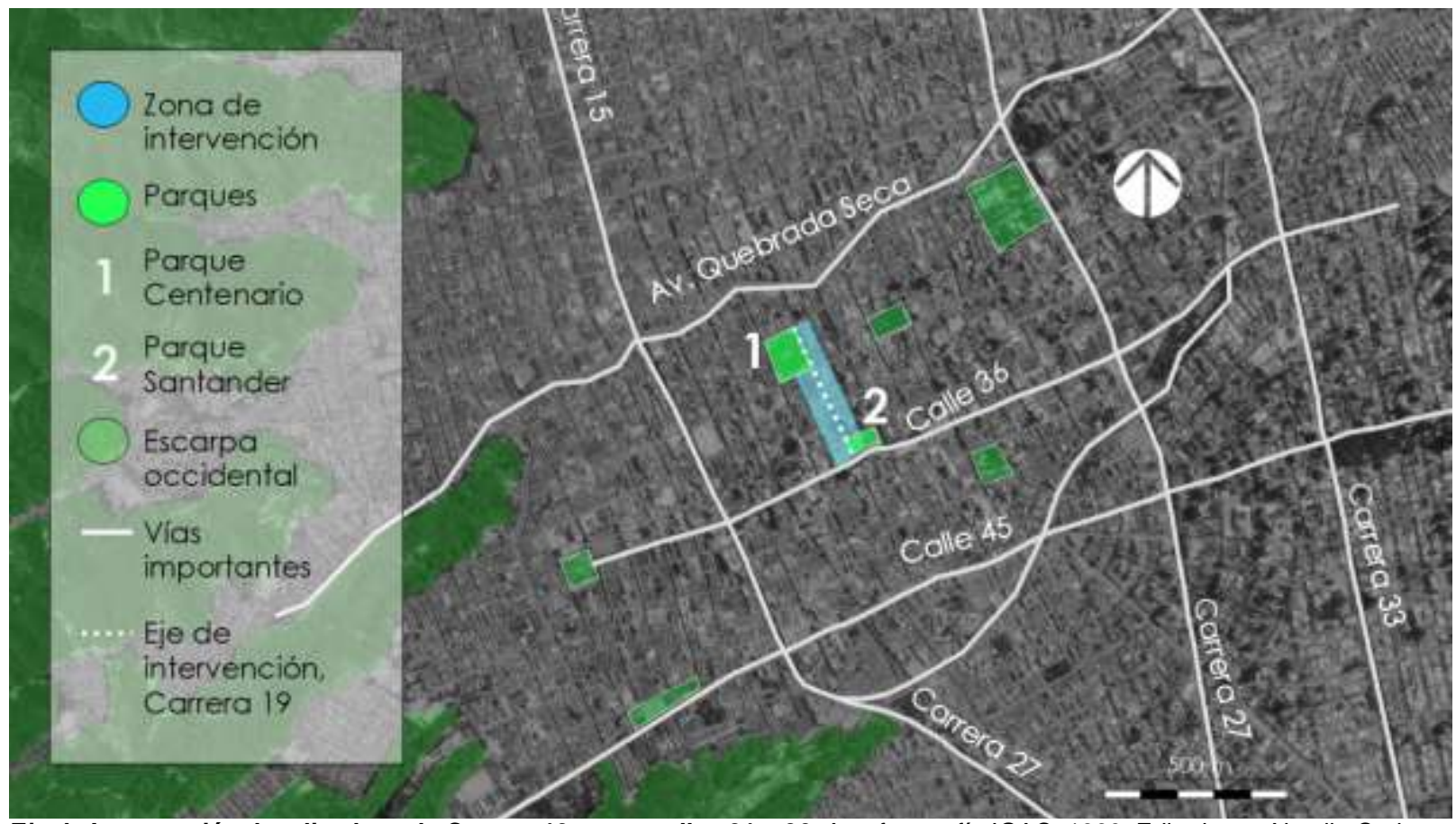

Eje de Intervención, localizado en la Carrera 19, entre calles 31 - 36. Aerofotografía IGAC, 1960. Editado por Natalia Cadena.

Con relación a lo anterior, actualmente el Plan de Ordenamiento Territorial - POT denota un modelo y visión, donde se destaca: "El espacio público como eje articulador". (Acuerdo No. 011, 2014 )Esto permite evidenciar la necesidad de realizar una intervención urbana con el fin de mejorar las condiciones del sector y la consolidación de este elemento, el eje de intervención, como interconector que tendrá repercusiones no solo en el sector centro y el municipio de Bucaramanga, sino en el Área Metropolitana de Bucaramanga - AMB (comprendida por los municipios de: Bucaramanga, Floridablanca y Piedecuesta), por la cobertura de servicios que este presta a la comunidad, en relación a, entidades gubernamentales: el Banco de la República, comerciales: la Cámara de Comercio, Centro de Negocios: La Triada, educativos: el Antiguo Hotel Bucarica y culturales y recreativos: el Centro Cultural del Oriente, el Teatro Santander y el Club del Comercio.

En consecuencia, se escoge al arquitecto urbanista Jan Gehl, como referente teórico por su concordancia entre la metodología que expone y el objetivo del proyecto, el autor indaga acerca de la interacción entre las personas y el espacio público a través del planteamiento de ocho herramientas (Counting, Mapping, Tracing, Tracking, Looking for traces, Photografing, Keeping a diary, Test Walks) basadas en la observación, que logran la formulación de propuestas mejorando las cualidades físicoespaciales y responden a la relación entre el usuario y lugar. (Gehl, J y Svarre, B., 2013)

Este ejercicio académico surge a partir de la siguiente hipótesis: El Eje de Interconexión entre el Parque Santander y el Parque Centenario en el Centro de Bucaramanga como elemento que conforma el espacio público, permitirá la transformación y revitalización del sector Centro de Bucaramanga. Desarrollada desde cuatro objetivos iniciando con una Conceptualización en la cual se esclarece la pertinencia y el planteamiento del proyecto; seguido de una Caracterización del marco histórico que se 
enfoca en la problemática del sector Centro y las dinámicas que han modificado el objeto de estudio. Unido a esto, tenemos el marco normativo y legislativo que regula la elaboración del diseño, así como la identificación de la zona de influencia e intervención, en este orden de ideas, la información se traduce en el Análisis y Diagnóstico que determina los insumos para la Formulación de la propuesta.

El resultado final es el planteamiento de una propuesta urbana bajo una mirada integradora del lugar con una visión histórica del contexto actual, priorizando la revitalización del espacio público desde la perspectiva de quien lo habita, el ciudadano.

\section{METODOLOGÍA}

El tipo de investigación realizada es cuantitativa, cualitativa y descriptiva. Cuantitativa, ya que, en la aplicación de las herramientas de Gehl, se mide la cantidad de peatones que transitan por el eje, a través de un conteo simple, en intervalos de tiempo de 10 minutos, en diferentes días; por otra parte, se realiza un levantamiento por medio de las mediciones de los elementos que configuran el espacio público del eje recreando una imagen actual de este, de estas dos premisas se hacen inferencias para el desarrollo de la propuesta de diseño. Cualitativa, puesto que valora las determinantes arquitectónicas que conforman el área de estudio para su posterior diseño. Y, descriptiva, ya que desde un ámbito académico analiza los antecedentes históricos del lugar y propone el diseño futuro, integrando las variables que afectan el sector Centro y determinan las características con que debe contar el eje de interconexión entre parques.

Para el logro de los objetivos del proyecto y esclarecimiento de la hipótesis se llevó a cabo la siguiente metodología; como primer acercamiento al tema, se generó una matriz de conceptos, de diversos autores estudiosos de la ciudad, permitiendo sintetizar conclusiones propias referentes a la propuesta. A su vez, se investiga la bibliografía de Jan Gehl para la comprensión de su metodología y reinterpretación de la misma como herramienta implementada en la identificación de la zona de intervención. De la misma forma, por la localización del proyecto (en el Centro Histórico de la ciudad y por las edificaciones patrimoniales e hitos arquitectónicos encontrados en el eje), se recrea históricamente la génesis del lugar, además de realizar un expediente urbano para el reconocimiento actual de los predios involucrados. Esta información podrá cuantificar las características del lugar y generar los insumos que conciban el diseño del eje a intervenir.

\subsection{Marcos de Referencia}

El proyecto se encuentra ubicado en el sector Centro de la ciudad de Bucaramanga, zona configurada por medio de los parques, elementos del espacio público que se transformaron no solo en sus características físicas, sino en la concepción simbólica que han tenido los habitantes de la ciudad acerca de estos. Es por ello que el eje de intervención, el cual comunica el Parque Santander con el Parque Centenario, se desprende de una red de parques que busca revitalizar el espacio público.

Por lo tanto, es importante en el desarrollo de la propuesta de diseño el conocimiento de la normativa actual, el Plan de Ordenamiento Territorial de Bucaramanga (POT), Plan Maestro de Movilidad Área Metropolitana de Bucaramanga, Manual del Espacio Público, y comprender algunos conceptos que enmarcan y encaminan el planteamiento.

2.1.1 Sector Centro: Es el sector ubicado en el Centro de Bucaramanga y comprendido entre al norte por la Avenida Quebrada Seca, al este con la carrera 27, al sur con la Avenida La Rosita y al oeste con la carrera novena (Sector Centro).

Se encuentra dentro del sector delimitado al norte por la Avenida Quebrada Seca, al este con la carrera 27, al sur con la Avenida La Rosita y al oeste con la carrera novena (Sector Centro).

Esta zona se escoge por su desarrollo histórico y por ser un lugar de constante flujo peatonal durante las horas del día, factor que se reduce en la noche puesto que, aunque existe mixtura de usos, las dinámicas se transforman y la seguridad disminuye. Esto hace que la complejidad de la zona sea mayor, 
variable que además exalta su importancia con respecto a la cobertura de servicios y equipamientos que brinda tanto al municipio como a su área metropolitana. Sin embargo, a pesar de la relevancia de la zona existe un desequilibrio marcado en la relación entre el espacio público y el construido.

2.1.2 Espacio público: Basado en los conceptos de Habermas, Borja y Jones, expuestos en "Espacio público, igualdad y civilización", se encuentra dentro de las definiciones de espacio público la constante en cuanto a dos componentes que constituyen estos espacios, el medio físico como elemento tangible y el elemento intangible referente a las relaciones entre los usuarios, aquel lugar que posibilita el encuentro. Sin embargo, en cuanto a la aplicación de este concepto en el proyecto se rescata, la postura de Borja en relación a la visión del espacio público como este espacio donde se logra la convergencia de lo diferente en un espacio de uso colectivo, común y accesible a todos.

Además, el espacio público por las actividades que allí convergen y los que lo habitan requiere de cualidades físico espaciales óptimas, que permitan un confort para el usuario, tanto en escala, como en aquellos elementos que lo configuran. (Peñalosa, s.f.)

2.1.3 Interconexión: Apoyado en las definiciones propuestas por Frick (2011), Santos y De las Rivas (2008), interconectar hace referencia a como se interrelaciona el sector Centro, teniendo en cuenta aquellos puntos de tensión y encuentro que articulan el espacio público y la integración de estos en relación al eje y la red de parques planteada en la propuesta.

2.1.4 Revitalización: Tomando como referencia los conceptos de Salingaros (2005), Bucheli(2012) y Encajes Urbanos (2011), se comprende la transcendencia de este concepto, en relación a la localización del proyecto, como la acción que encamina la propuesta, hacia una visión que permita la reestructuración y transformación del eje desde la diversidad social y cultural de quienes lo habitan, integrada a la conectividad del sector, generando un impacto positivo que potencialice el centro de la ciudad.

2.1.5 Red de Parques: Según el Plan de Ordenamiento Territorial de Bucaramanga, la red de parques es la conformada por los espacios verdes que buscan la conexión de la estructura ecológica principal con el área urbana y brindan soporte a la calidad de vida a través de la provisión de áreas destinadas para la recreación, contemplación, encuentro y ocio de los ciudadanos. Según su superficie, cobertura, función, usuarios, equipamientos y accesibilidad se clasifican en parques de escala regional, metropolitana, zonal, locales y de bolsillo. (Consejo de Bucaramanga, 2014)

\subsection{Referente Teórico}

En la elección del referente teórico, se realizó un comparativo en las metodologías propuestas por tres urbanistas: Kevin Lynch, Salvador Rueda y Jan Gehl porque sus planteamientos se concentran en una visión pensada en el peatón para el abordaje del espacio público, y con esto se escogió el de mayor pertinencia para aplicación de un enfoque metodológico en el desarrollo de la propuesta. Este comparativa tuvo en cuenta las variables: objetivo del método de cada autor, las herramientas que propone, los recursos que se requieren para su realización, la duración y si estas metodologías han sido usadas en el diseño urbano o no.

Encontrando que el objetivo del método que es coherente con lo que busca la propuesta; realizar una intervención urbana encaminada y orientada a la interconexión y revitalización en el espacio público, es el propuesto por Jan Gehl, pues el de Kevin Lynch se enfoca en las percepciones de una muestra determinada de personas, y no estudia su interacción con el espacio público, y el método de Salvador Rueda determina la sostenibilidad del lugar objeto de estudio. Mientras que Jan Gehl en su método busca el estudio de la vida pública y el mejoramiento del espacio público.

Por otro lado, en las herramientas y recursos necesarios, el método de Kevin Lynch es inviable para el desarrollo de la intervención porque la disposición de expertos requeriría un gasto que no puede sustentar un estudiante, y además la aplicación de la entrevista requiere bastante tiempo y varias personas idóneas que puedan realizar las preguntas y la aplicación. Mientras que los métodos de Salvador Rueda y Jan Gehl se pueden hacer entre una o dos personas. 
En relación a la duración el método de Kevin Lynch requiere bastante tiempo, teniendo en cuenta el tiempo dispuesto para la elaboración del análisis urbano, teniendo en cuenta que esta etapa no debe pasar de entre 1 y 4 meses para su elaboración.

Sin embargo, aunque los métodos de Jan Gehl y Salvador Rueda tienen grandes ventajas, lo más importante es hacia dónde va y cuál es su objetivo metodológico y la propuesta de Gehl está totalmente relacionada con el planteamiento del proyecto de grado.

En consecuencia, al profundizar sobre el enfoque de Jan Gehl en libros como La humanización del espacio urbano y Ciudades para la gente, entre otras de sus publicaciones, se comprende su metodología, su mirada de la ciudad y cómo esta debe brindar a sus habitantes las herramientas para que puedan desarrollar diversas actividades no solo las necesarias sino las sociales y sobretodo las opcionales. (Gehl, J. 2009)

Al examinar el planteamiento del Gehl, se establecen tres momentos en su metodología, en primera instancia los interrogantes que posibilitan la reflexión con respecto de cuáles son los aspectos más relevantes de analizar, así mismo plantea ocho herramientas basadas en la observación que permiten acercarse a la realidad de la vida urbana y poder caracterizarla en aras de proyectar iniciativas de mejora de espacios públicos de una forma más acertada en relación con las dinámicas cotidianas de los usuarios. (Gehl y Svarre, 2013)

Se expondrán dos figuras una que explica la utilidad de las preguntas y otra que describe las herramientas que el autor propone.

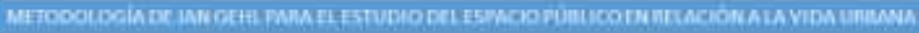
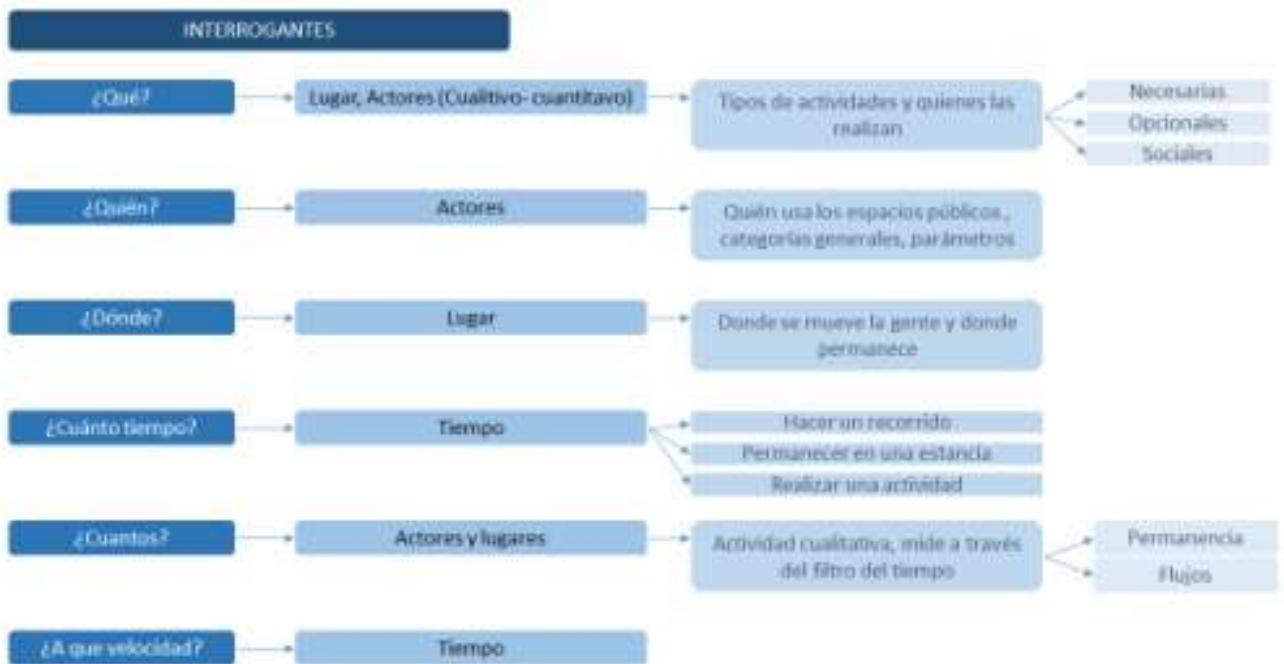

Tiemo

Interrogantes propuestos por Gehl en su metodología. Fuente: (Gehl, J y Svarre, B., 2013) Elaborado: Natalia Cadena. 


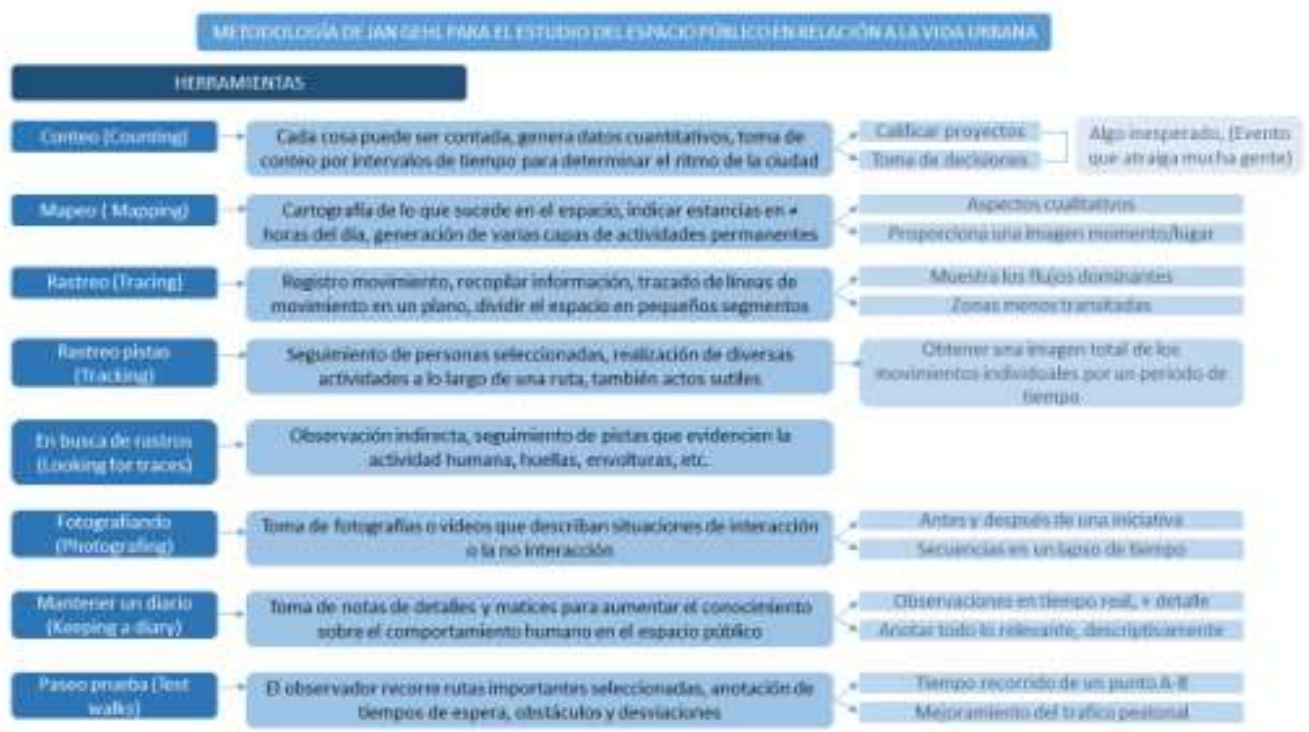

Herramientas propuestas por Jan Gehl en su metodología. Fuente: (Gehl, J y Svarre, B., 2013) Elaborado: Natalia Cadena.

Y un tercer momento que sería la aplicación de las herramientas en la identificación del lugar: Conteo (Counting) y Rastreo (Tracing) para comprender las dinámicas de uso del espacio público que tienen los ciudadanos al transitar por el eje de estudio.

En la aplicación de la herramienta Counting, se identifican previamente los tipos de conteo de personas que existen: Intersección: el cual sirve para definir la clase de cruce peatonal, Puerta: se realiza en un tramo de un eje viario y los encargados del conteo se sitúan en cada extremo de este, para determinar el número de personas que entre y sale por estos puntos, como si fuese una puerta, y Volantes: la persona que realiza el conteo se desplaza a lo largo un trayecto contando el número de personas que se cruzan con él. (Núñez, 2016, párr. 4,5 y 6).

En este caso se realizó el conteo tipo puerta, ya que el objeto de estudio es un tramo de un eje vial. Realizando las mediciones así, en el eje de estudio: Carrera 19, entre calles 31-36 y en un tramo dentro del eje en la Carrera 19, entre calles 33 - 35. Se toman como referencia una fecha de alta y una de baja concurrencia de personas: el 23 de diciembre 2017 y el 01 de enero de 2018, respectivamente, donde se realizaron 3 conteos de 10 min por tramo, para un total de 60 min por los dos tramos, 120 min por los dos días de conteo y un total de 1249 personas contadas, observando dos tipos de variables de medición; tipo de peatón: peatón, ciclista, coche de bebe y silla de ruedas; edad y género: niños de 0-6 años, 7-14 años, 15-29 años jóvenes, 30-44 años adulto joven, 45-59 años adulto, 60-74 años adulto mayor y más de 75 años tercera edad, esta última categoría es una percepción de lo observado por la persona que realizo el conteo.

Igualmente, se aplicó la herramienta Tracing en los siguientes cruces viales: Carrera 19 con calle 31 , Carrera 19 con calle 33, Carrera 19 con calle 34, Carrera 19 con calle 35 y Carrera 19 con calle 36, en las fechas del 23 de diciembre 2017 y el 01 de enero de 2018. La aplicación de esta herramienta consistió en llevar planos impresos de cada cruce y durante 3 lapsos de 10 min, observar y trazar en dicho plano los recorridos realizados por los peatones en el momento de cruzar la calle. Las mediciones en la aplicación de estas dos herramientas se describen en la sección de Resultados.

\subsection{Antecedentes Históricos}

El sector Centro se vislumbra desde dos miradas, en primera instancia en relación a su proceso de ocupación histórica dentro del periodo comprendido entre el año 1908 a 1965 basado en la Documentación Histórica de Santander - Universidad Industrial de Santander (UIS), y por otra parte se 
desarrolla una línea del tiempo que compila las fechas que sitúan en la historia las edificaciones relevantes del lugar y el proceso de configuración de cada parque que compone la red.

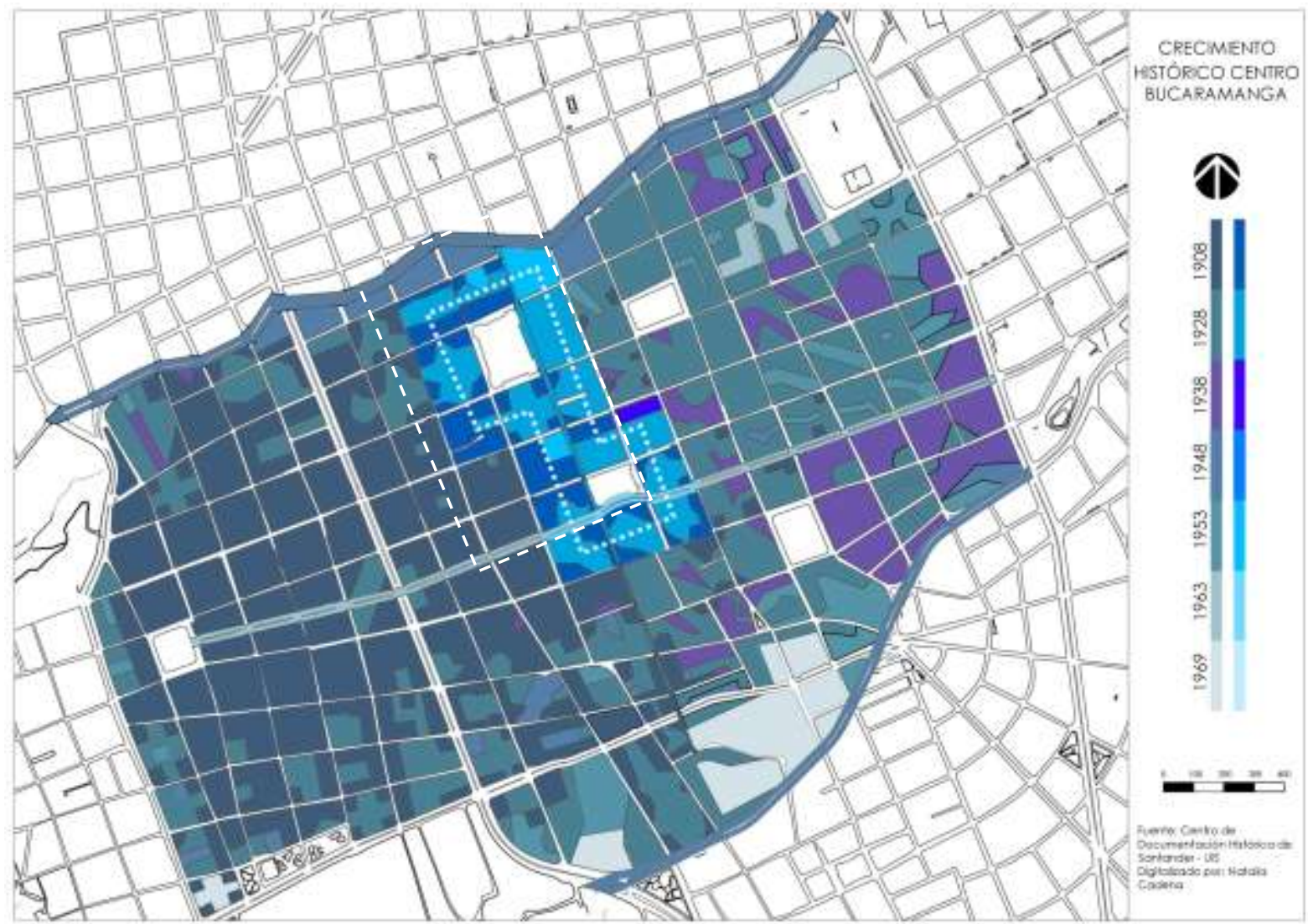

Crecimiento histórico de Bucaramanga. Fuente: Planos de Crecimiento Urbano ubicados en el Centro de Documentación Histórica de Santander - UIS, 1975. Elaborado: Natalia Cadena.

Al observar el plano se encuentra en qué momento se configuro la carrera 19, entre $1908-1928$ principalmente, y a su vez el Sector Centro. 


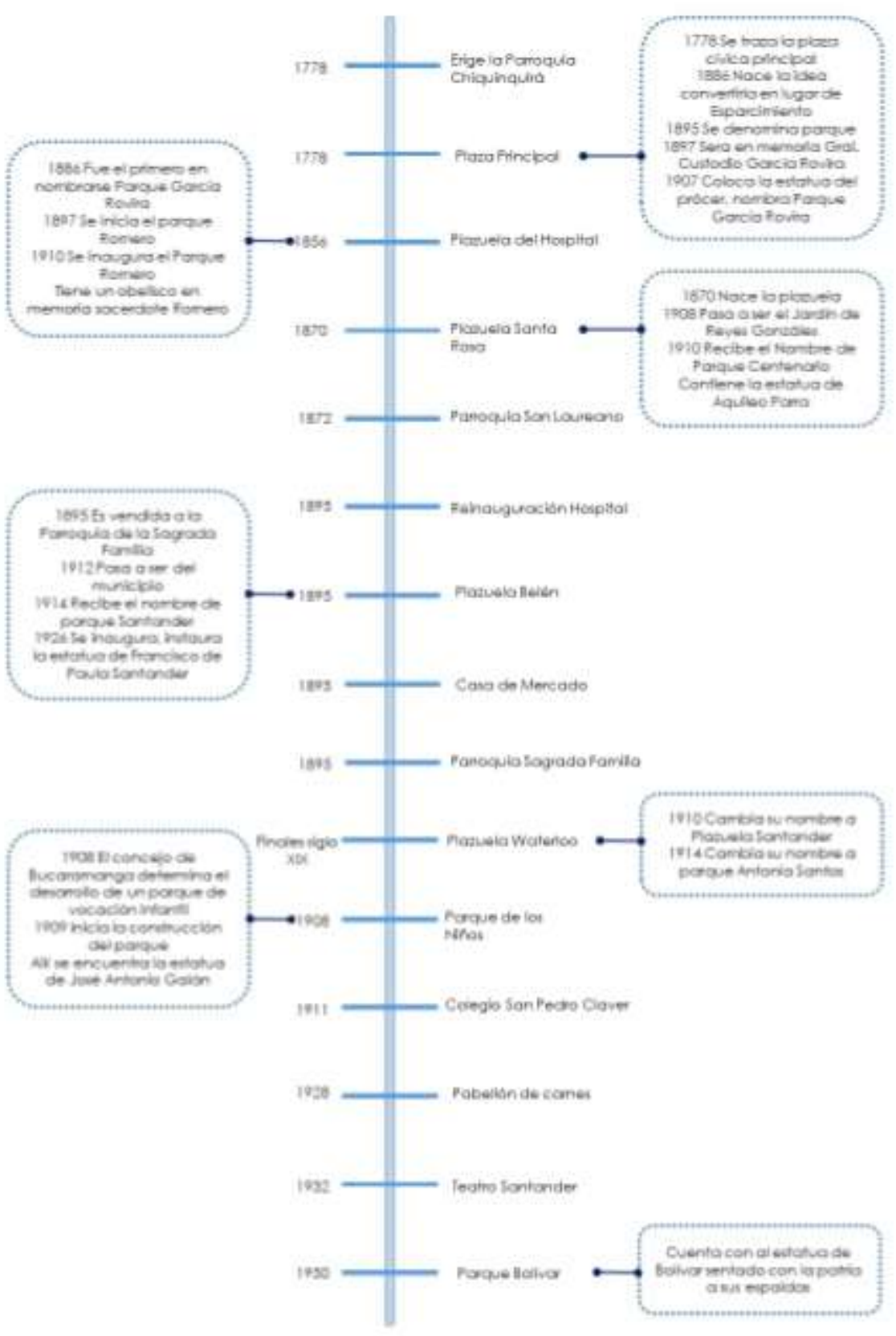

Línea del tiempo, parques del centro de Bucaramanga. Fuente: (Revista Santander, 2009), (Sevilla,2011). Elaborado: Natalia Cadena.

La línea del tiempo denota, en el caso de los parques: Romero, García Rovira, Centenario, Santander y Antonia Santos, se consolidaron inicialmente como plazas y plazuelas, a diferencia de los parques: Bolívar y Parque de los Niños, los cuales se concibieron inicialmente como parques. Sin embargo, es relevante aclaran que la diferencia entre plaza, plazuela y parque definida en el Marco Referencial de este artículo, no es la razón de la denominación específica, pues fueron sus habitantes, quienes por imitación de los modelos europeos (como elemento de civismo que embellece la ciudad y representaba el orgullo por los héroes de la patria), decidieron denominar parques a las plazuelas y plazas que existían en el sector. (Revista Santander, 2009)

\subsection{Análisis Urbano}


En el análisis urbano se establecieron dos panoramas de acotación el Sector Centro y la Zona de Intervención.
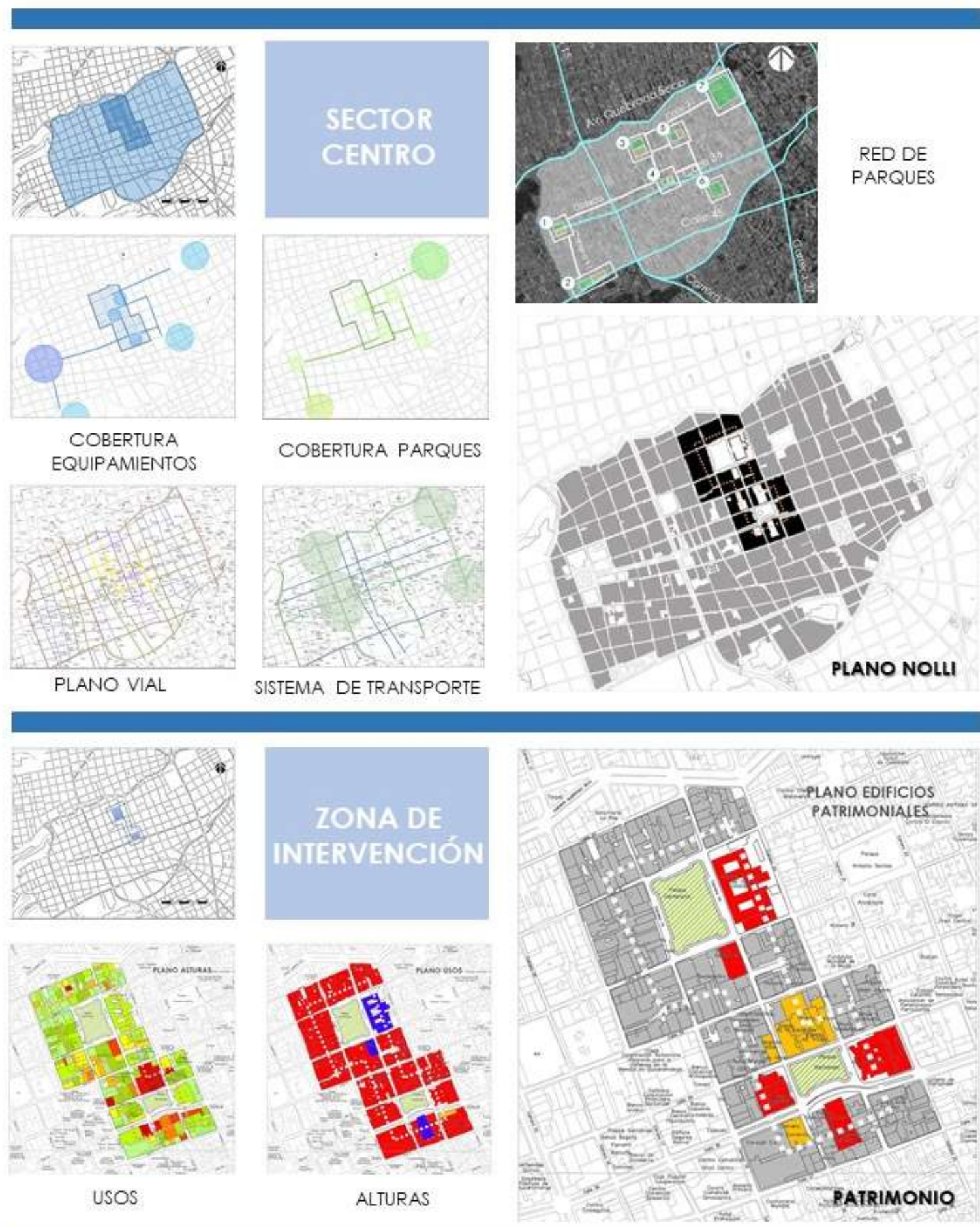

Análisis Urbano. Elaborado por: Natalia Cadena 2018. 
La puesta en marcha del análisis urbano, se llevó a cabo a través de salidas de campo, con cartografía del lugar y toma de evidencia fotográfica, para posibilitar, complementar y soportar la recopilación de la información obtenida.

Asimismo, considerando la relevancia y la repercusión de la intervención del eje de diseño con respecto a la ciudad de Bucaramanga y su Área Metropolitana, es necesario el análisis del Sector Centro para interpretar aquellas variables que logren el planteamiento de una conexión acertada y congruente con las dinámicas urbanas propias del lugar. Por esta razón, se establecieron como categorías de estudio: la cobertura de Equipamientos, siendo este un sitio de un gran número de equipamientos; la cobertura de parques, como elementos de articulación del espacio público; el plano vial, comprendiendo la movilidad vehicular; el sistema de transporte, reconociendo los puntos de mayor afluencia de personas y constante tránsito de buses urbanos; el trazado propuesto para la red de parques, obteniendo una propuesta de interconexión entre ellos y el plano Nolli, plano de origen Italiano, donde se vislumbran las relaciones entre el espacio público y semipúblico, conexiones claves en el desarrollo de la zona.(La nuova topografia di Roma..., 2010)

A su vez y cambiando de escala se analiza el área de intervención, comprendida por el eje de la carrera 19 entre calles 31 a 36 y los predios al este y oeste de la misma, para la cual se identificaron las categorías de usos, alturas y edificaciones patrimoniales, posibilitando la comprensión de los elementos que enmarcan y determinan la configuración físico espacial que conforma el eje de carácter público.

\section{RESULTADOS}

Durante el proceso de aplicación de las herramientas propuestas por el referente teórico, se obtienen los siguientes resultados:

\subsection{Counting}

En la siguiente tabla se contemplan la cantidad de personas contadas en el eje de estudio: Carrera 19, entre calles 31-36, totalizadas de la variable tipo de peatones.

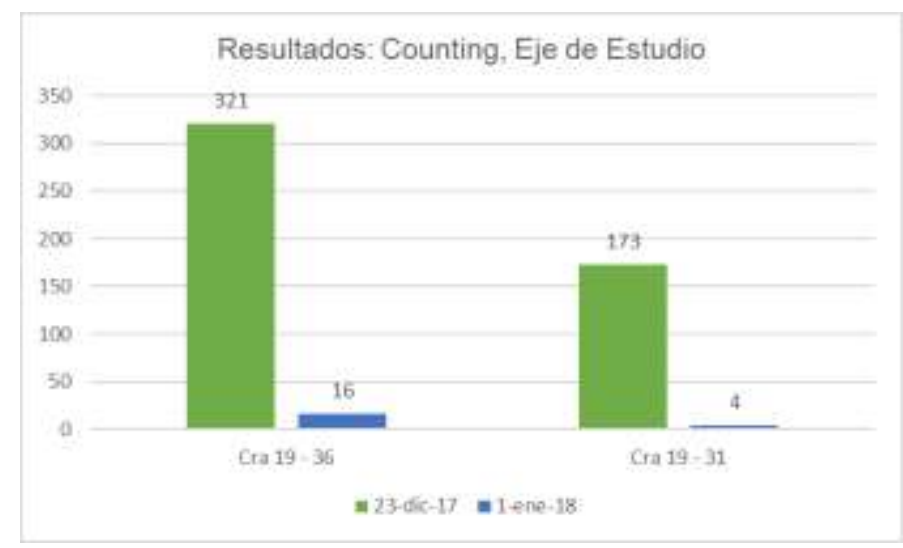

Resultados: Counting, Eje de Estudio. Elaborado por Natalia Cadena.

Siendo el día de menor flujo peatonal el primero de enero, se evidenció un número mayor de personas en el conteo realizado en el eje de estudio, sin embargo, en el día de mayor flujo peatonal el 23 de diciembre, se contabilizaron mayor número de personas en el tramo de la carrera 19 entre calles 35 - 33.

A continuación, se exponen los resultados obtenidos en el tramo dentro del eje: en la Carrera 19, entre calles $33-35$. (total variable tipo de peatones). 


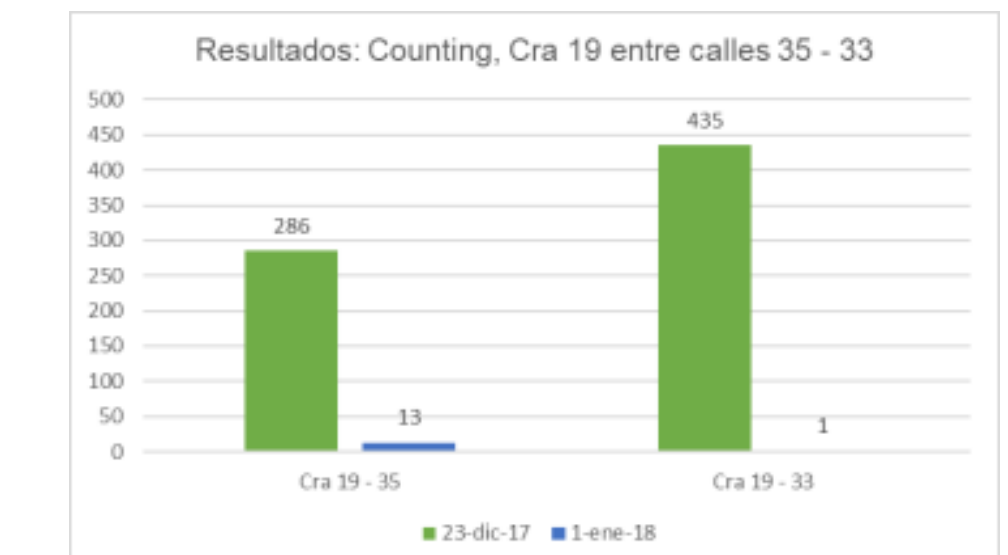

Resultados: Counting, Cra 19 entre calles 35 - 33. Elaborado por Natalia Cadena.

Al observar las figuras 23 y 24 se encuentra que tanto el día 23 de diciembre de 2017 como el 01 de enero de 2018 el número de personas que entro y salió por cada puerta es distinto, eso quiere decir que las personas no recorren todo el tramo o que entran en alguno de las edificaciones a lo largo del eje.

Dentro del mismo conteo se tuvieron en cuenta los datos de edad y género, para comprender qué tipo de población suele transitar por el eje y el tramo del eje en estas dos fechas, para la categoría de edad, se tomaron las siguientes variables, niños de 0-6 años, niños 7-14 años, jóvenes entre $15-29$ años, adulto joven entre $30-44$ años, adulto entre 45 - 59 años, adulto mayor entre $60-74$ años y tercera edad de 75 años en adelante.

En el conteo del eje de estudio en los días 23 de diciembre de 2017 y 01 de enero de 2018, en la puerta de la carrera 19 calle 36 esquina del Parque Santander se obtienen los resultados que se muestran a continuación (Teniendo en cuenta la variable de edad):

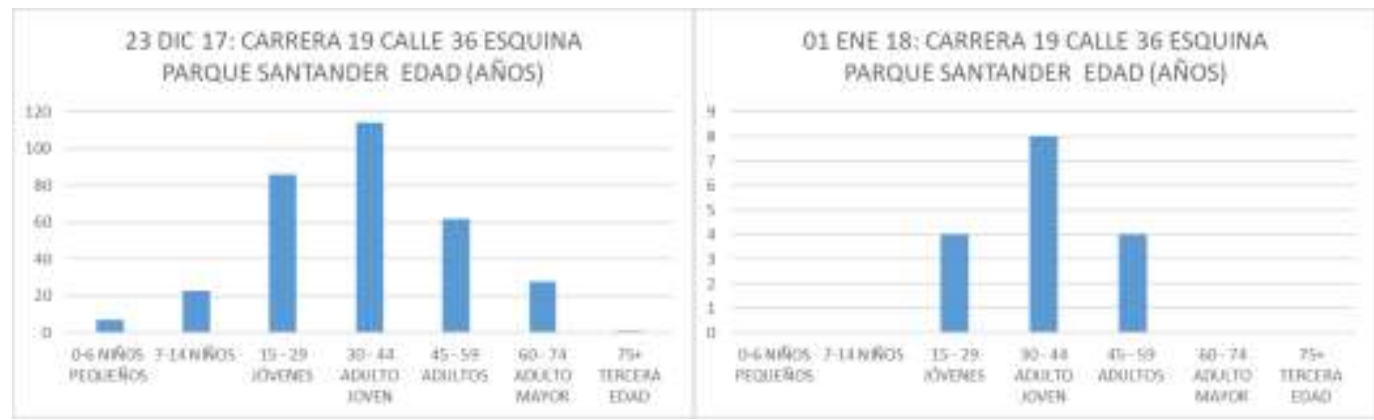

Resultados de conteo por edad en la Carrera 19 con calle 36. Elaborado por Natalia Cadena.

En el conteo del eje de estudio en los días 23 de diciembre de 2017 y 01 de enero de 2018, en la puerta de la carrera 19 calle 31 esquina del Parque Centenario se obtienen los resultados que se muestran a continuación: 


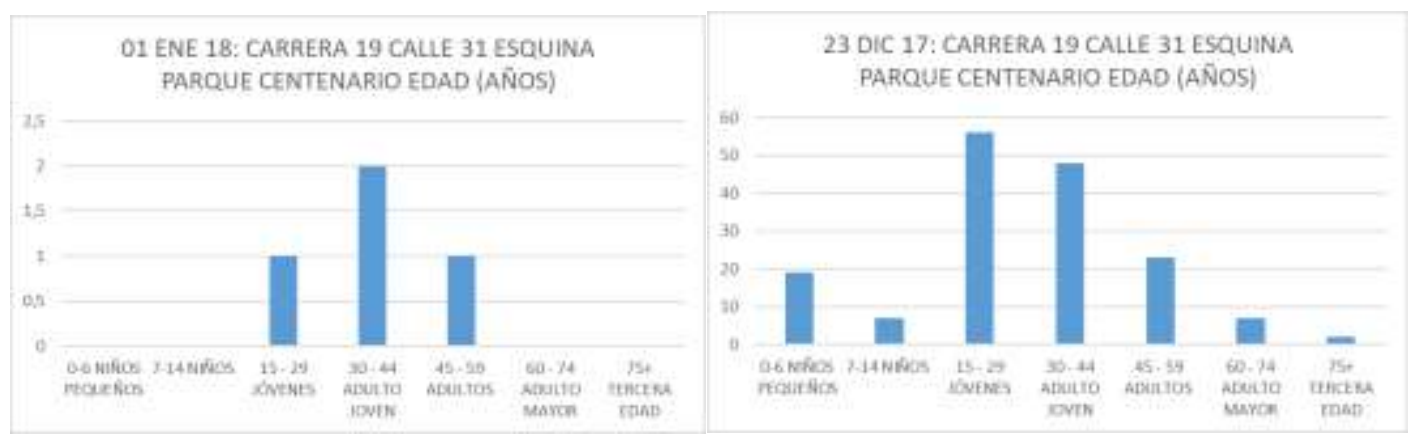

Resultados de conteo por edad en la Carrera 19 con calle 31. Elaborado por Natalia Cadena.

En estas graficas se observa que la edad de población que predomina en este cruce, el día 23 de diciembre de 2017 está entre el rango de edad de 15- 29 años y el día 01 de enero de 2018 está en el rango de 30 - 44 años de edad, adulto joven, a su vez es notorio que para el día 01 de enero el rango de edad que se observar transitar por ese eje es entre $15-59$ años, y que no se observan ni niños ni personas mayores.

En el conteo del tramo dentro del eje de estudio en los días 23 de diciembre de 2017 y 01 de enero de 2018, en la puerta de la carrera 19 calle 35 esquina del Parque Santander se obtienen los resultados que se muestran a continuación (Teniendo en cuenta la variable de edad):

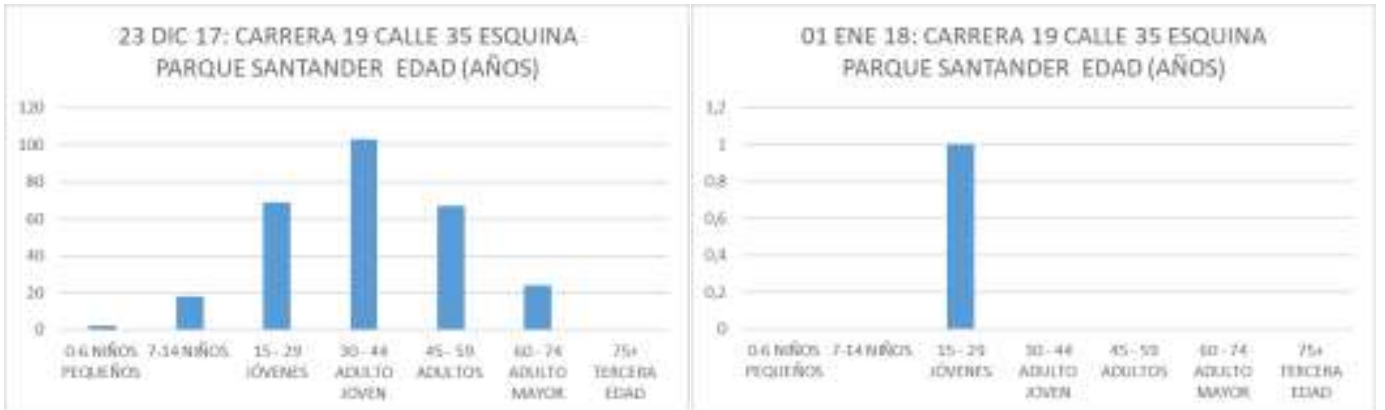

Resultados de conteo por edad en la Carrera 19 con calle 35. Elaborado por Natalia Cadena.

En estas graficas se observa que el en el conteo del día 23 de diciembre de 2017 el grupo etario que predomina es de 30 a 44 años, o adulto joven. Pero en cambio el 01 de enero de 2018 solo se observa una persona entre el rango de 15 a 29 años, es importante resaltar que ese día las personas que se encontraban en la zona eran habitantes de calle, que estaban consumiendo sustancias psicoactivas.

En el conteo del tramo dentro del eje de estudio en los días 23 de diciembre de 2017 y 01 de enero de 2018, en la puerta de la carrera 19 calle 33 esquina del Parque Santander se obtienen los resultados que se muestran a continuación:

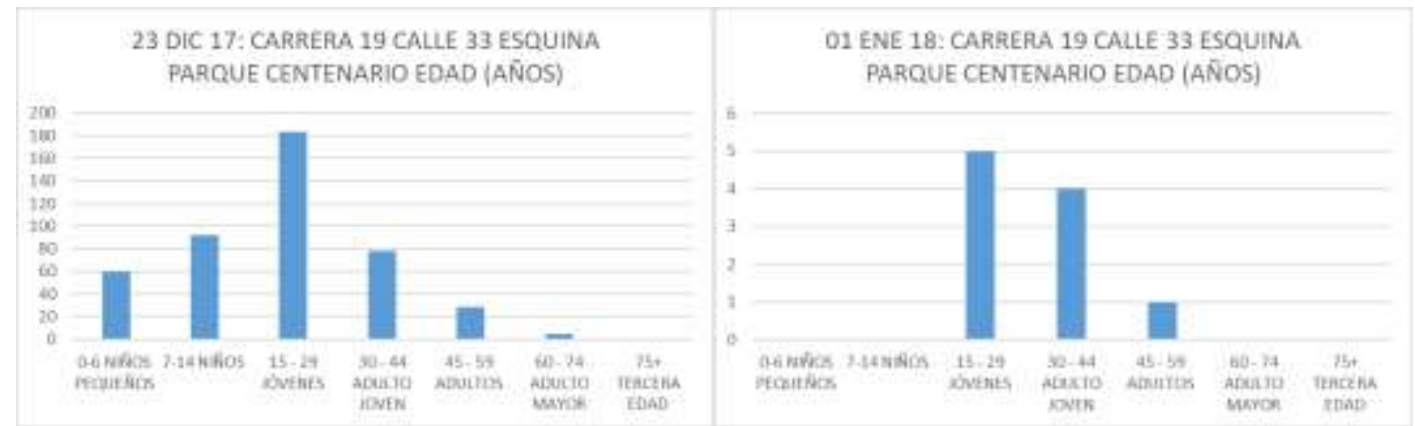

Resultados de conteo por edad en la Carrera 19 con calle 33. Elaborado por Natalia Cadena. 
En estas graficas se observa que la edad de población que predomina en este cruce es la que se encuentra en el rango de 15 - 29 años de edad, adulto joven, a su vez es notorio que para el día 01 de enero el rango de edad que se observar transitar por ese eje es entre $15-59$ años, y que no se observan ni niños ni personas mayores.

\subsection{Tracing}

En la siguiente grafica se muestra la compilación de los resultados encontrados en la aplicación de la herramienta tracing en los cruces viales: Carrera 19 con calle 31, Carrera 19 con calle 33, Carrera 19 con calle 34 , Carrera 19 con calle 35 y Carrera 19 con calle 36 , encontrados dentro del eje de estudio.

\section{URACING 24 DE DJCJEMBRE 2017/ CRUCES EJE DE JNIERVIENCIÓN}
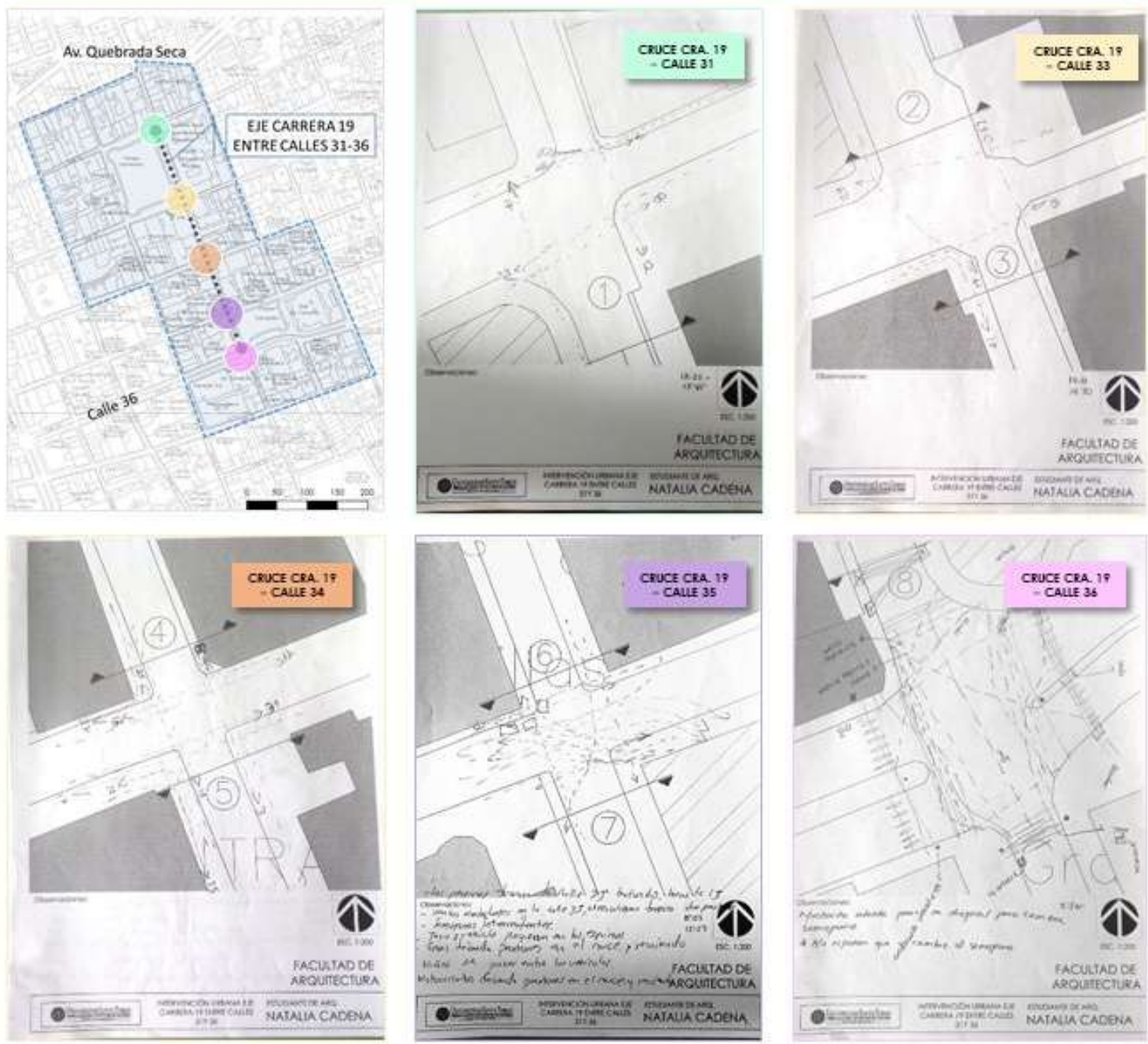

Resultados de la aplicación de la Herramienta Tracing - 24 de diciembre 2017. Elaborado: Natalia Cadena.

En estos resultados se identifican los cruces neurálgicos dentro del eje, los cuales deben tener un desarrollo distinto en su propuesta de diseño para asegurar un paso seguro de peatones, el primero es el cruce de la carrera 19 con calle 35, punto de remate del tramo peatonal de la calle 35 entre carreras 15 y 19, culminando en el parque Santander y el segundo es el cruce de la carrera 19 con calle 36 , siendo la calle 36 un vía de constante flujo vehicular que además cuenta con cuatro carriles, dos en sentido este y oeste y dos en sentido oeste y este, donde se observó en la aplicación de la herramienta a algunos peatones que pasar de un punto a otro en forma diagonal o por fuera del paso establecido para las personas en las esquinas. 


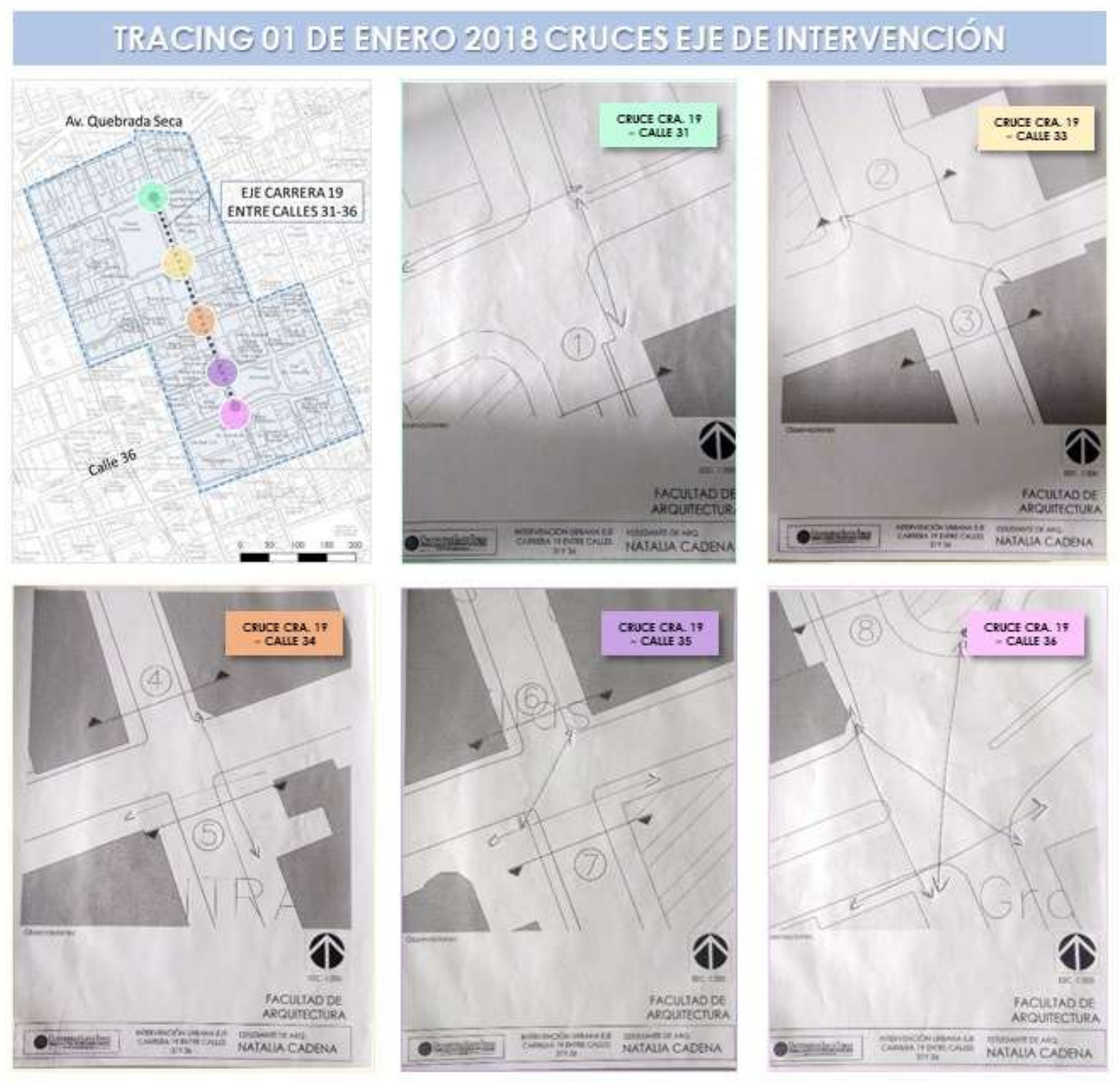

Resultados de la aplicación de la Herramienta Tracing - 01 de enero 2018. Elaborado: Natalia Cadena.

Los resultados obtenidos reafirmaron la forma de cruzar de las personas errada en los cruces de la carrera 19 con calle 35 y el cruce de la carrera 19 con calle 36, sin embargo, en el cruce de la carrera 19 con calle 33 se encuentra también una forma irregular de realizar el cruce por un peatón, pero, es importante destacar que a diferencia del día 24 de diciembre de 2017, cuando se realizó la primera aplicación, el día primero de enero es un día de baja afluencia tanto de peatones como de vehículos.

\section{CONCLUSIONES Y PROPUESTA DE DISEÑO}

En efecto el espacio público es el elemento que articula y transforma el sector centro de Bucaramanga, le da vida al sector, sin embargo, este como elemento integrador, necesita un ejercicio de comprensión y análisis de todas las variables que lo componen no solo en la actualidad sino desde sus orígenes. Además, el tipo de intervención que se llevará a cabo en el eje, debe ser versátil pues en el que se encuentra existen diversas dinámicas, ritmos y ciclos repetitivos a lo largo del año; es por eso que la intervención propuesta contempla todas estas variaciones, se interpretan y se desarrollan de forma atemporal, con un planteamiento de sistemas por escalas yendo del eje de intervención al Sector Centro, donde se ilustran los principios de zonas verdes, el sistema vial y los usos predominantes. 
Por ello, se retoman el Plan Centro propuesto por el por el Departamento Administrativo de Planeación Municipal (Narváez, 1986), donde se buscaba repotenciar el Centro de la ciudad, mediante una subdivisión por medio de cuadrantes y la consolidación del sistema de espacios públicos. Esto unido al concepto de Supermanzana propuesto por La Agencia de Ecología Urbana de Barcelona (s.f.) y reinterpretándolo al contexto de la ciudad de Bucaramanga, permiten orientar la propuesta de diseño y vislumbrar el Centro a futuro.

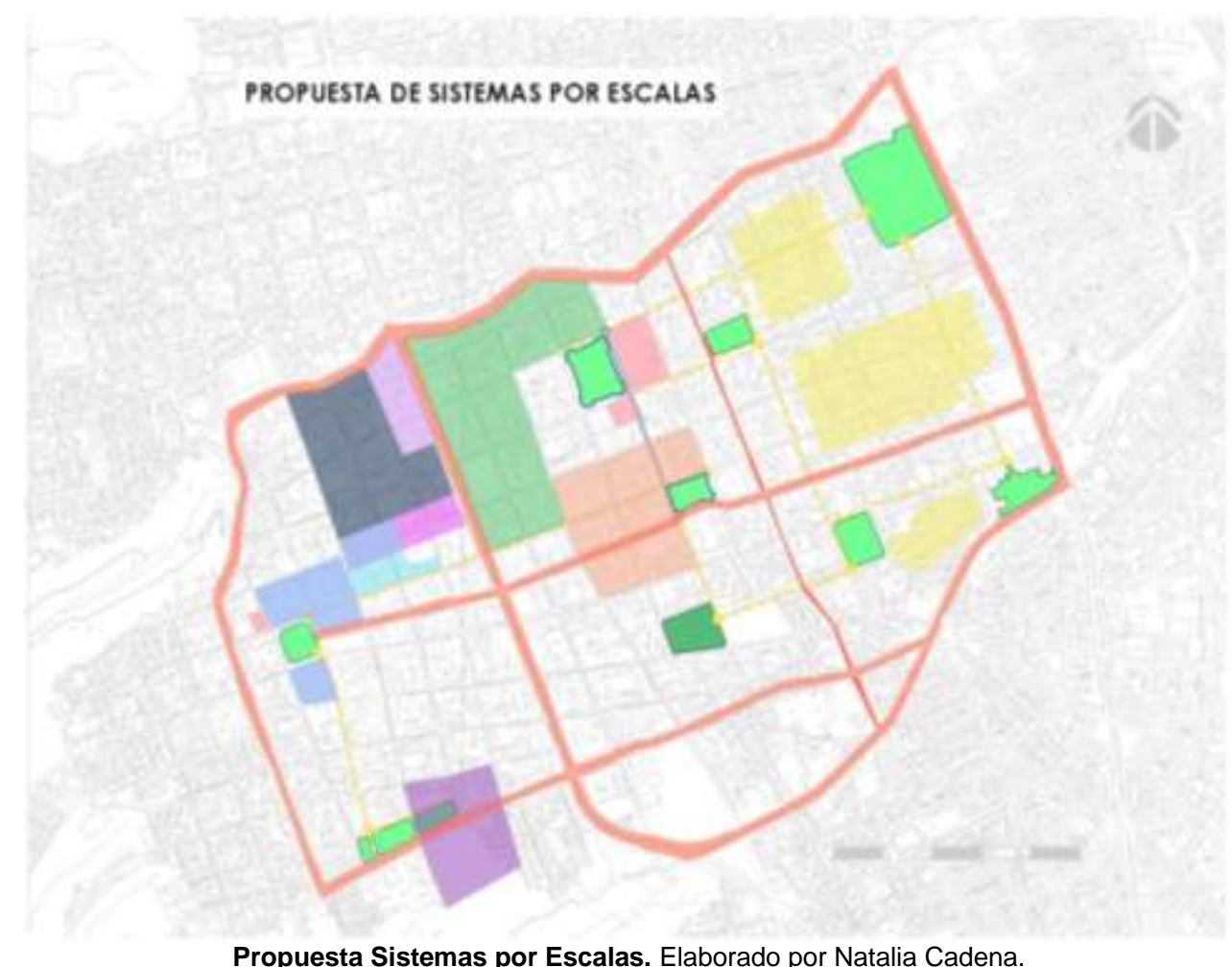

Propuesta Sistemas por Escalas. Elaborado por Natalia Cadena.

El planteamiento de Sistemas por escalas para El Sector Centro de Bucaramanga, se desglosa primero en el Principio de Sistema Vial. El cual busca la subdivisión del Sector Centro a través de vías de primer y segundo orden, en cuadrantes con un promedio de 25 manzanas, que permitan una movilidad más eficaz, trasladando el trafico frecuente a estas vías, liberando las manzanas al interior de cada cuadrante, en relación a este principio, se propone la Carrera 21, como vía de segundo orden que subdivida los cuadrantes entre la carrera 15 y la carrera 27, permitiendo a su vez acortar las distancias entre estas vías. 


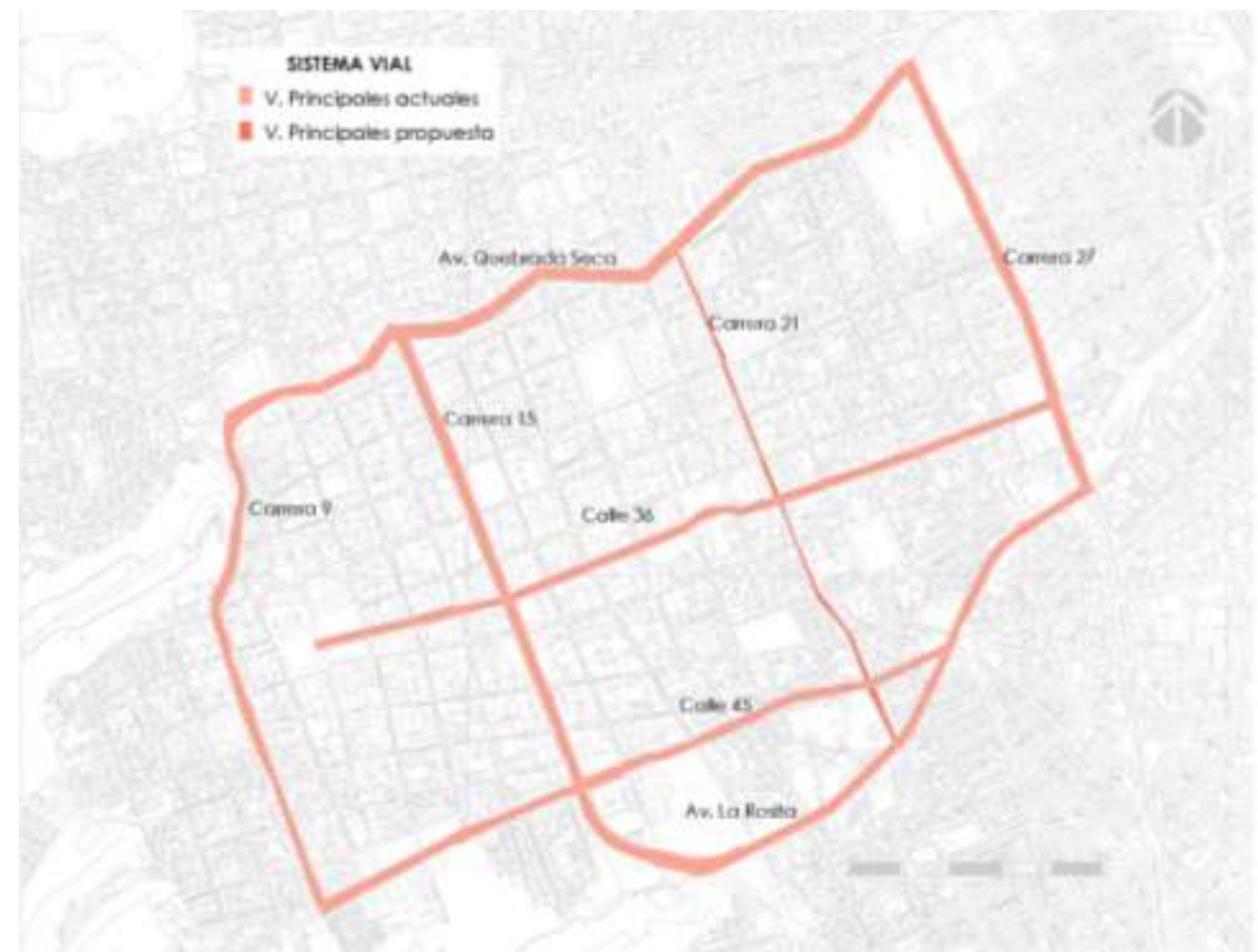

Sistema Vial, Sistema por escalas. Fuente: Narváez, 1986. Elaborado por Natalia Cadena.

Por otra parte, se identifican los usos predominantes existentes en el sector Centro, pues articulan los principios de Sistema Vial y Zonas Verdes.

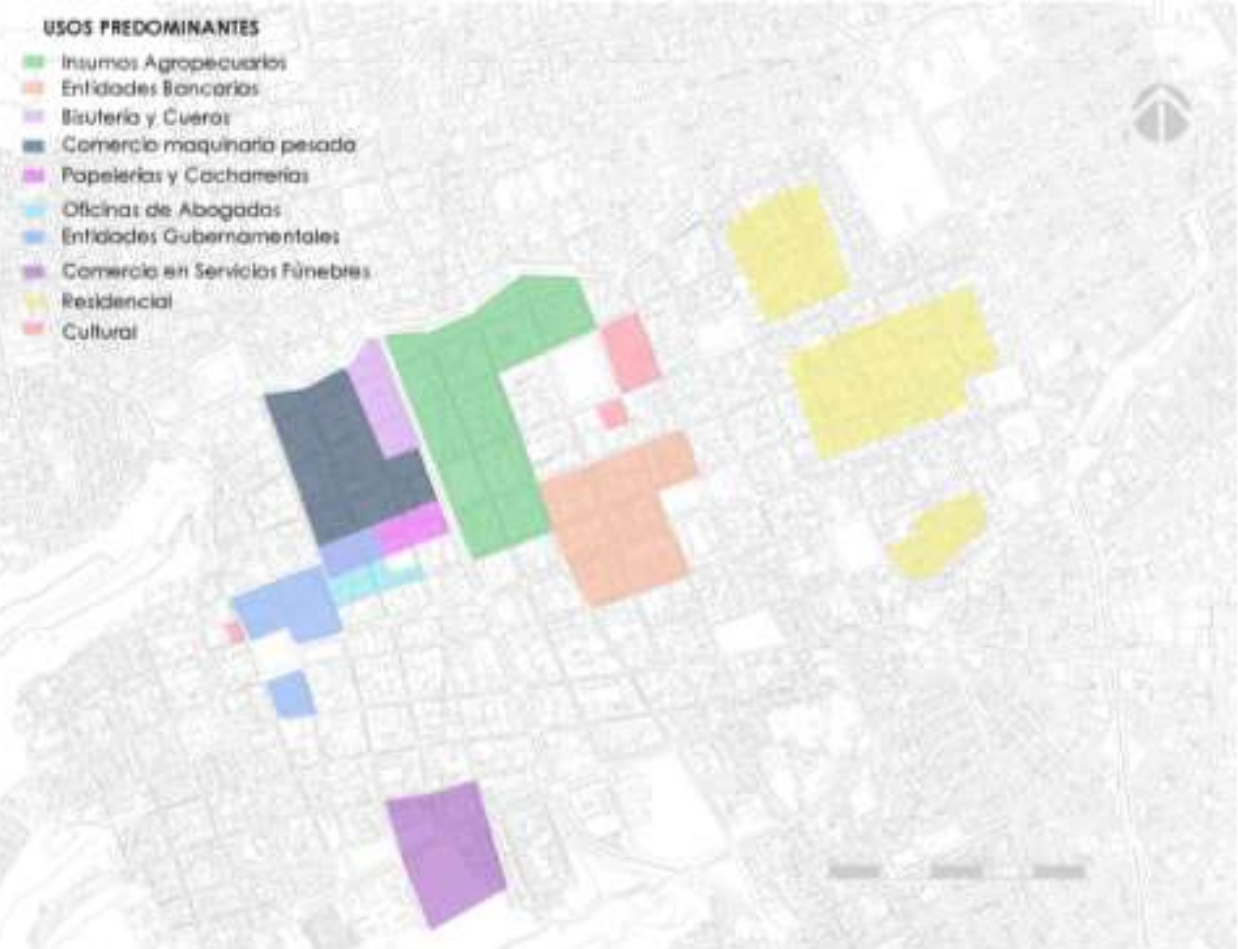

Usos predominantes, Sistemas por Escalas. Elaborado por Natalia Cadena. 


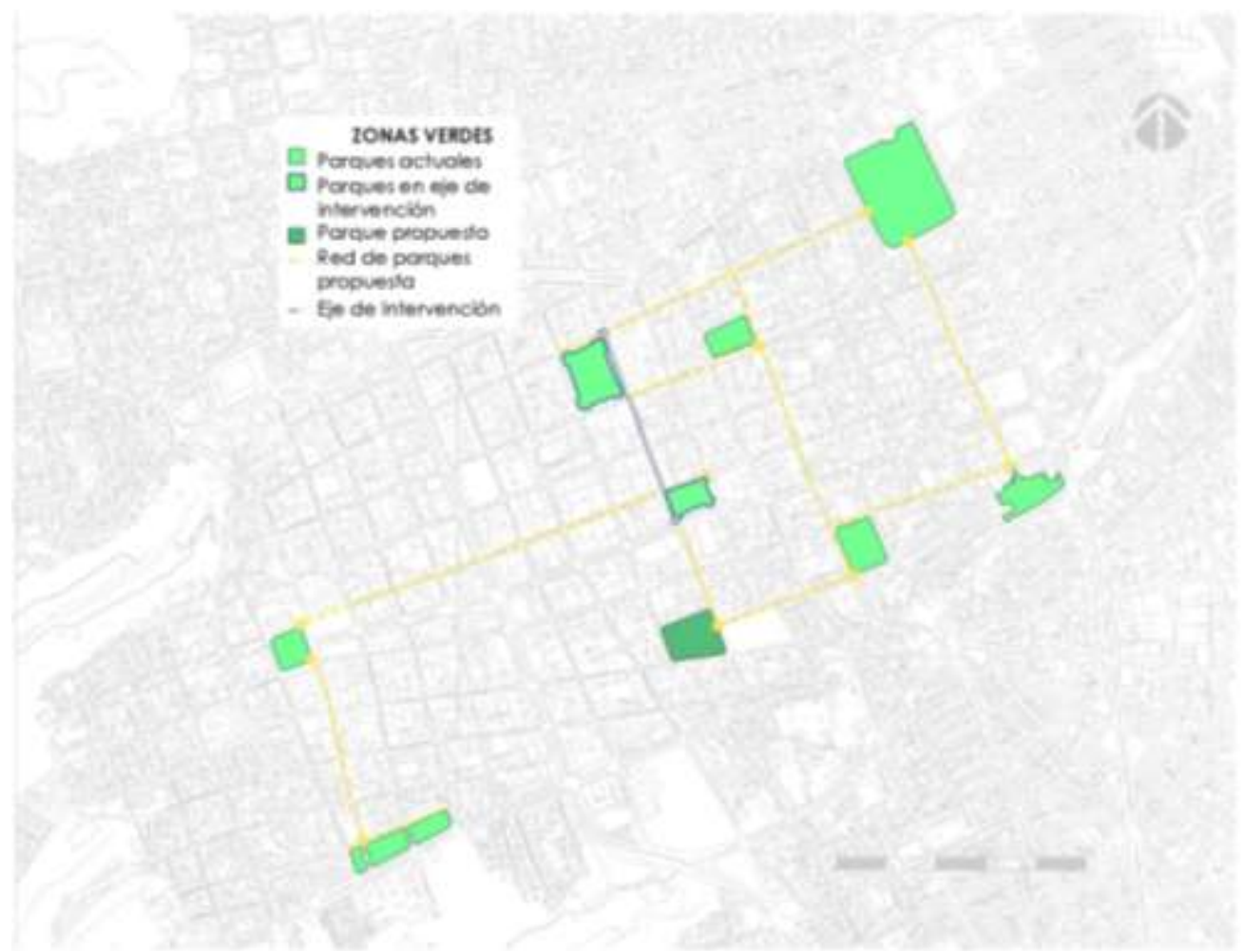

Zonas Verdes, Sistemas por Escalas. Elaborado por Natalia Cadena.

Finalmente, se propone la red de Zonas verdes. La cual interconecta los parques de Sector Centro, donde se resalta la conexión entre el parque Santander y el parque Centenario, Eje de Intervención, como una primera fase, y la continuación de la red se proyecta a futuro. Así como la proposición de un nuevo parque para el cuadrante delimitado entre la carrera 15 y la carrera 21 y las calles 36 y 45 , el cual sirve de remate a un pasaje comercial deprimido y a futuro consolida el eje de la carrera 19 desde la carrera 31 hasta la carrera 41 , como un eje peatonal que conecta tres parques del Sector.

En adición, teniendo en cuenta lo anterior y profundizando en el cuadrante en el cual se desarrolla el eje, se toma como referencia la Super Manzana, realizando un paralelo entre el ideal de este concepto y su reinterpretación para la ciudad de Bucaramanga.

El concepto de Supermanzana, expresa: "(...) son células urbanas de unos 400 por 400 metros, en cuyo interior se reduce al mínimo el tráfico motorizado y el aparcamiento de vehículos en superficie, y se da la máxima preferencia a los peatones en el espacio público. El tráfico motorizado circula por las vías perimetrales, mientras las calles interiores se reservan al peatón y, en condiciones especiales, a cierto tipo de tráfico como vehículos de residentes, servicios, emergencias, carga y descarga." (Agencia de Ecología Urbana de Barcelona, 2012, Modelo Conceptual, párr. 2)

Sin embargo, por el funcionamiento del cuadrante donde se encuentra el eje, se reinterpreta de la siguiente forma, se estipulan las vías perimetrales de mayor tráfico, la Av. Quebrada Seca, la Calle 36 y las Carreras 15 y 21. Las calles y carreras internas de este cuadrante, se proponen solo para tráfico específico de la zona, priorizando el tráfico peatonal. A su vez, las calles 31 (en sentido oriente occidente) y 33 (en sentido occidente - oriente), se priorizan solo para tránsito de bus urbano, esto con el fin de acortar las distancias de los peatones y respetando las dinámicas del cuadrante en relación al constante flujo de personas, que llegan a este punto a los focos de actividad cultural que allí existen y las personas que se desplazan a sus veredas luego de la compra de insumos agrícolas. 


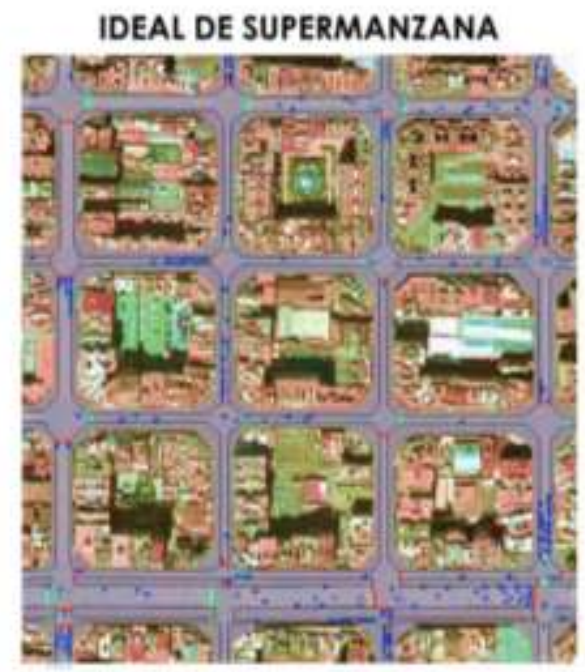

\section{REINTERPRETACIÓN SUPERMANZANA}

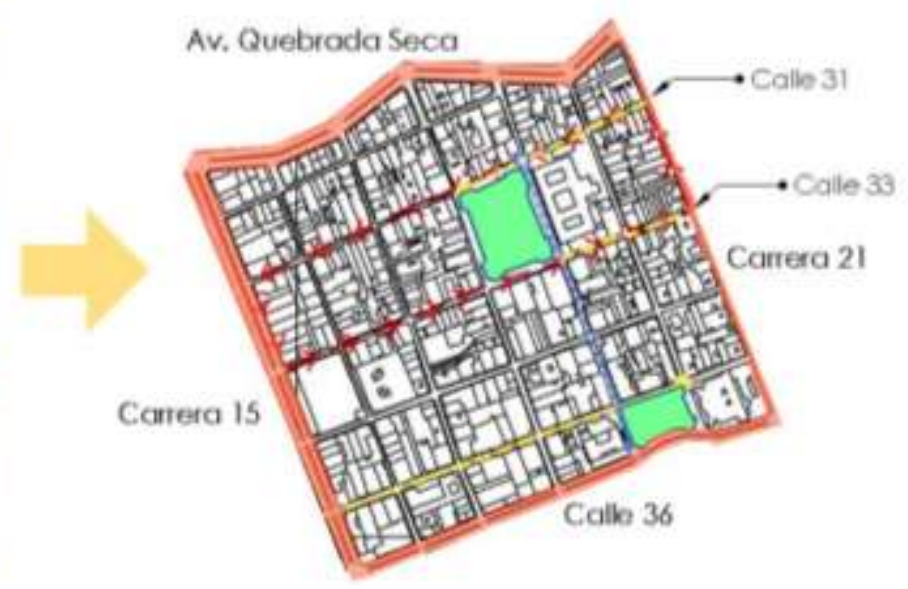

Paralelo Ideal Supermanzana y Reinterpretación Supermanzana. Fuente: Editado por Natalia Cadena.

En conclusión y respondiendo a la hipótesis planteada originalmente en el ejercicio de investigación, se puede afirmar que el eje de Interconexión entre el Parque Santander y el Parque Centenario en el Centro de Bucaramanga como elemento que conforma el espacio público, permite la transformación y revitalización del sector Centro de Bucaramanga, ya que su futuro desarrollo, diseño y vocación contemplarán las variables del sector al que hace parte, configurándolo de tal forma que cambiará el paradigma actual de área en deterioro, a una nueva imagen de ciudad en la que lo histórico, patrimonial, económicos y político, derivado en un foco de actividades contundentes que puede repotenciarse y ser pensado en el imaginario colectivo como un lugar de disfrute de las personas y no de prioridad vehicular.

\section{BIBLIOGRAFÍA}

Acuerdo No. 011. Concejo de Bucaramanga, Bucaramanga, Colombia, 21 de mayo de 2014.

Área Metropolitana de Bucaramanga. (2011). Plan Maestro de Movilidad, Área Metropolitana de Bucaramanga 2011-2030. Bucaramanga, Santander, Colombia.

Planos de Crecimiento Urbano ubicados en el Centro de Documentación Histórica de Santander, Universidad Industrial de Santander, 1975.

Dieter, F. (2011). Una Teoría del Urbanismo. Bogotá: Universidad del Rosario. (Pág. 52-55, 79-88)

Gehl, J. (2009). La Humanización del Espacio Urbano. Barcelona: Reverté.

Gehl, J. y Svarre, B. (2013). How to Study Public Life. Washington: Island Press.

Narváez, J. (1986). Edificio Plurifuncional. Universidad Santo Tomas.

Peñalosa, E. (s.f.). Espacio público, igualdad y civilización. Bogotá: Universidad de los Andes.

Sevilla, D. (2011) Utopía y realidad: la mutualidad en Bucaramanga. (tesis de maestría), Universidad Nacional de Colombia.

Salingaros, N. A. (2005). Principles of Urban Structure. Design Science Planning.

Santos, L y De las Rivas J. (2008). Ciudades con atributos: conectividad, accesibilidad y movilidad. 19. Universidad de Valladolid.

Universidad Industrial de Santander. (2009). Dossier de Parques. Revista Santander, 24-79.

\section{FUENTES ELECTRÓNICAS}


Agencia de Ecología Urbana de Barcelona, (2012). Modelo Conceptual. párr.2.

http://www.bcnecologia.net/es/modelo-conceptual/supermanzana (Consulta: 13/02/2018)

Bucheli, J. (2012). Lineamientos para la formulación de políticas públicas de revitalización urbana. Una oportunidad para repensar y proyectar los centros urbanos en el contexto Posmetropolitano. (tesis maestría), Pontificia Universidad Javeriana. https://repository.javeriana.edu.co/handle/10554/11497. (Consulta: 21/02/2018)

Encajes urbanos, (2011.) Definir un concepto a través de una imagen, un texto y un video para el proyecto colectivo "Glosario de Reciclaje Urbano". https://encajesurbanos.com/2011/12/12/revitalizacionazoteas-colectivas/ (Consulta: 18/02/2018)

La nuova topografia di Roma Comasco de Giambattista Nolli, ca. 1692-1756, s.f. http://tectonicablog.com/?p=9019 (Consulta: 20/02/2018)

Nuñez, S. (2016). ¿Cómo se mide el número de peatones que pasan por una calle?, párr. 4,5 y 6, Consultado el 13 de diciembre de 2017 del sitio Web ecomovilidad.net:

https://ecomovilidad.net/global/como-se-mide-el-numero-de-peatones-que-pasa-por-una-calle/ 